\title{
Relationships between non-communicable disease, social isolation and frailty in community dwelling adults in later life: findings from the Hertfordshire Cohort Study
}

\author{
Gregorio Bevilacqua ${ }^{1}$ (D) Karen A. Jameson ${ }^{1} \cdot$ Jean Zhang ${ }^{1} \cdot$ Ilse Bloom $^{1,2,3}$ (D) Nicholas R. Fuggle $^{1}$ (I) \\ Harnish P. Patel ${ }^{1,2,3,4}$ (D) Kate A. Ward ${ }^{1}$ (D) . Cyrus Cooper ${ }^{1,5}$ (D) Elaine M. Dennison ${ }^{1,6} \mathbb{D}^{D}$
}

Received: 7 October 2021 / Accepted: 7 November 2021 / Published online: 29 November 2021

(c) The Author(s) 2021

\begin{abstract}
Background Social relationships play a fundamental role in individuals' lives and health, and social isolation is prevalent among older people. Chronic non-communicable diseases (NCDs) and frailty are also common in older adults.

Aims To examine the association between number of NCDs and social isolation in a cohort of community-dwelling older adults in the UK, and to consider whether any potential association is mediated by frailty.

Methods NCDs were self-reported by 176 older community-dwelling UK adults via questionnaire. Social isolation was assessed using the six-item Lubben Social Network Scale. Frailty was assessed by the Fried phenotype of physical frailty.

Results The median (IQR) age of participants in this study was 83.1 (81.5-85.5) years for men and 83.8 (81.5-85.9) years for women. The proportion of socially isolated individuals was $19 \%$ in men and $20 \%$ in women. More women (18\%) than men (13\%) were identified as frail. The number of NCDs was associated with higher odds of being isolated in women (unadjusted odds ratio per additional NCD: $1.65,95 \%$ CI 1.08, 2.52, $p=0.021)$, but not in men, and the association remained robust to adjustment, even when accounting for frailty (OR 1.85, 95\% CI 1.06, 3.22, $p=0.031$ ).

Discussion Number of self-reported NCDs was associated with higher odds of social isolation in women but not in men, and the association remained after considering frailty status.

Conclusions Our observations may be considered by healthcare professionals caring for community-dwelling older adults with multiple NCDs, where enquiring about social isolation as part of a comprehensive assessment may be important.
\end{abstract}

Keywords Ageing $\cdot$ Multimorbidity $\cdot$ Non-communicable diseases $\cdot$ Older people $\cdot$ Social Isolation $\cdot$ Frailty

Cyrus Cooper

cc@mrc.soton.ac.uk

Elaine M. Dennison

emd@mrc.soton.ac.uk

1 MRC Lifecourse Epidemiology Centre, University of Southampton, Southampton General Hospital, Southampton SO16 6YD, UK

2 NIHR Southampton Biomedical Research Centre, University of Southampton, Southampton, UK

3 University Hospital Southampton NHS Foundation Trust, Southampton, UK

4 Medicine for Older People, University Hospital Southampton, Southampton, UK

5 National Institute for Health Research Musculoskeletal Biomedical Research Unit, University of Oxford, Oxford OX3 7LE, UK

6 Victoria University of Wellington, Wellington, New Zealand

\section{Background}

Social relationships are important in individuals' lives and health, and have previously been associated with physical and psychological wellbeing [1]. Social isolation is considered as an objective measure of the scarcity or absence of regular social contacts and relationships with relatives, friends and neighbours and lack of social connection and involvement with the wider society [2-4]. As such, social isolation is distinct from loneliness, which is intended as a subjective, negative evaluation of the discrepancy between one's desired and actual quantity and quality of social relationships [5-7]. Previous studies reported that social isolation is prevalent and increasing among older adults [8, 9]. This is a growing public health concern, as social isolation has been associated with a number of both physical and psychological adverse health outcomes, such as poor 
physical capability, myocardial infarction, stroke, depression and mortality [10-16]. Therefore, recent studies have highlighted the importance of developing and implementing interventions aimed at reducing social isolation (as well as loneliness) in older populations $[17,18]$.

In addition, an increase in life expectancy and a subsequent ageing population have led to a higher prevalence of chronic, non-communicable diseases (NCDs) [19]. The coexistence of two or more NCDs in one patient is defined as multimorbidity $[20,21]$, a phenomenon that increases with age [22]: a study utilising a survey of members of a health maintenance organisation aged 65 and over, found the average person had 8.7 chronic diseases [23], while a Canadian study reported that the number of chronic diseases varies from 2.8 in young patients to 6.4 among older patients recruited from regional general practices [24]. The World Health Survey carried out between 2002 and 2004 in 70 countries worldwide showed that about $50 \%$ of middle-aged (50-64 years) to older ( $\geq 65$ years) adults were multimorbid, having two or more NCDs, approximately a quarter had three, and one tenth have four or more NCDs [25]. A study by Kingston et al. using data from two population-based English cohorts of older adults living in the community (i.e. the English Longitudinal Study of Ageing [ELSA] and the Cognitive Function and Ageing Studies II) reported a $45.7 \%$ prevalence of multimorbidity (defined as having two or more NCDs) in 2015 for individuals aged 65-74 years, and estimated that such prevalence might increase to $52.8 \%$ by 2035 [26].

While a number of studies focused on the link between multimorbidity and loneliness [27-32], studies looking at potential associations between the number of coexisting NCDs and social isolation are very rare. A recent systematic review of observational studies examining the link between multimorbidity and loneliness, social isolation, and social frailty (i.e. the lack of resources to meet one's basic social needs) highlighted the lack of studies examining the association between multimorbidity and social isolation [33].

The occurrence of NCDs in older adults is often accompanied by frailty $[34,35]$, a multi-dimensional geriatric syndrome that can be defined as a state of increased vulnerability resulting from decreased physiological reserves, multi-system dysregulation and limited capacity to maintain homeostasis $[36,37]$. Frailty is associated with higher risks of falls, disability, hospitalisation and mortality [38], and it has been reported to predict increased social isolation [39]. It is thus possible that any link between NCDS and social isolation might be mediated by frailty.

In the current study, we, therefore, investigated whether the number of self-reported NCDs is associated with social isolation in a cohort of community-dwelling older adults in the UK. We also sought to explore whether any observed associations were removed by adjustment for the presence of frailty.

\section{Methods}

Participants were recruited from the Hertfordshire Cohort Study (HCS), a population-based sample of men and women born between 1931 and 1939 in Hertfordshire and originally recruited to study the relationship between growth in infancy and the subsequent risk of adult diseases [40, 41]. Between 2019 and 2020, 176 participants from the HCS (94 men and 82 women) were visited at home by a trained fieldworker who administered a questionnaire that included information on medical history, medication use, lifestyle and social isolation. The visits also included measurements of height and weight to calculate body mass index (BMI); grip strength assessed three times for each hand using a Jamar dynamometer (the maximum measurement was used for analysis) [42]; the performance of the Short Physical Performance Battery (SPPB) tests, which included the assessment of gait speed, measured using an eight-foot course with no obstructions for an additional foot at either end. Participants were asked to walk at their customary pace and the time taken was recorded using a stopwatch; the use of assistive devices, such as canes, was permitted if necessary; gait speed was determined by dividing the distance traversed by the time between the first and last step [43].

Social isolation was assessed using the 6-item Lubben Social Network Scale (LSNS-6), which has been validated to assess social networks and social support and to screen for social isolation in older people [44]. The LSNS-6 tool measures the number and frequency of social interactions with friends (three items) and family members (three items). Each answer is assigned a score ranging from 0 ("none") to five ("nine or more"), and the overall final score ranges from 0 (indicating high isolation or few social resources) to 30 (indicating low isolation or many social resources). Social isolation was defined as a LSNS-6 score $<12$, in accordance with Lubben et al. [44]. The LSNS-6 has been shown to have good internal consistency across samples of communitydwelling older adults [44-46].

Number and types of NCDs were assessed by asking the question: 'Have you been told by a doctor that you have any of the following conditions?'. The following conditions were recorded: high blood pressure, diabetes, lung disease (asthma, COPD, emphysema, chronic bronchitis), rheumatoid arthritis, multiple sclerosis, cancer, vitiligo, depression, Parkinson's disease, heart disease (heart attack, angina, heart failure), peripheral arterial disease (claudication), osteoporosis, thyroid disease, and stroke. Any other serious illnesses were also recorded. 
Frailty was defined as the presence of at least three of the following Fried frailty criteria [38]: unintentional weight loss, weakness, self-reported exhaustion, slow gait speed and low physical activity. Weight loss was assessed asking the question: 'In the past 3-6 months, have you lost any weight unintentionally? If yes, how much?'. Weakness was defined as a maximum grip strength of $<27 \mathrm{~kg}$ for men and $<16 \mathrm{~kg}$ for women [47]. Exhaustion was assessed asking the following question: 'How often in the last week did you feel "everything I did was an effort" or "I could not get going?". Participants who responded to feel as described above for either moderate amounts or most of the time were identified as exhausted. Slow gait speed was defined as $\leq 0.8 \mathrm{~m} / \mathrm{s}$. Physical activity was assessed by the average amount of time (in minutes per day) spent walking outside, cycling, gardening, playing sports or doing housework in the last 2 weeks. Low physical activity was defined as an activity time in the bottom fifth of the HCS sex-specific distribution ( $\leq 58 \mathrm{~min} /$ day for men and $\leq 90 \mathrm{~min} /$ day for women). Frailty assessed using Fried's criteria has predictive validity for adverse health outcomes, including disability $[38,48]$.

Smoker status was categorised as never smoked, exsmoker or current smoker depending on the participants' answers to the questions 'Do you currently smoke?' and 'Have you ever been a smoker?'. Participants were asked how often they currently drank different types of alcohol (beer, wine, spirits, etc.) and how much they normally drank each time. This was used to estimate their alcohol consumption in units per week. Marital status was also ascertained and dichotomised for analysis as 'currently married' and 'single, divorced, separated or widowed'. Lastly, social class was determined at HCS baseline study (1998) from the participants' current or most recent occupation for men and never-married women, and of the husband for married women; occupations were classified as non-manual (classes I-IIINM) or manual (classes (IIIM-V) according to the 1990 OPCS Standard Occupational Classification scheme.

\section{Statistical analysis}

Descriptive statistics for continuous variables were expressed as median and interquartile range (IQR); categorical variables were expressed as frequency and percentage. Differences between men and women were assessed using Mann-Whitney tests, Pearson's $\chi^{2}$ tests or Fisher's exact test, as appropriate. Logistic regression analyses were used to examine the associations between the number of NCDs and the social isolation outcome. The regression analyses were undertaken with and without adjusting for the following demographic and lifestyle confounders: age, BMI, social class, marital status, smoker status and alcohol consumption and then further adjusted for frailty. A $p$ value of $\leq 0.05$ was considered to be statistically significant. The analyses were conducted using Stata version 16.

\section{Results}

Data on NCDs, social isolation, and frailty were available for 176 participants ( 94 men and 82 women). Table 1 provides the demographic characteristics of the participants. The median (IQR) age of participants in this study was 83.1 (81.5-85.5) years for men and $83.8(81.5-85.9)$ years for women. BMI was slightly higher in men (median 27.3, IQR 24.9-29.8) than in women (26.2, 23.7-29.3), although the difference was not statistically significant. The median (IQR) number of NCDs was 2 (1-2) in men and $2(1-3)$ in women, and essentially equal proportions of men (19\%) and women $(20 \%)$ were identified as socially isolated on the LSNS-6, while more women (18\%) than men (13\%) were identified as frail according to Fried's criteria. None of these differences, however, were statistically significant, the main significant differences being that men were more likely to be currently married compared to women ( $72 \%$ vs $48 \%$, $p<0.001$ ), consumed more alcohol units in a week than women (median 2.8, IQR 0.2-8.6 for men and 1.0, 0.0-4.4 for women, $p=0.006$ ) and counted fewer subjects who had never smoked (54\% of men and $70 \%$ of women, $p=0.053$ ). Table 1 also presents the number and proportion of participants with each of the NCDs.

Table 2 displays relationships between the number of NCDs and social isolation. There was no association between the number of conditions and being isolated in men, before or after adjustment. In contrast, a greater number of NCDs was associated with higher odds of being isolated in women in the unadjusted model (OR per additional NCD $1.65,95 \%$ CI $1.08,2.52, p=0.021)$. This association persisted after adjustment for confounders, i.e. age, BMI, social class, marital status, smoker status and alcohol consumption (OR 1.93, 95\% CI 1.11, 3.34, $p=0.020$ ), and it remained robust when Fried frailty was added to the model (OR 1.85, $95 \%$ CI 1.06, 3.22, $p=0.031$ ). Finally, we also considered whether these relationships were altered after adjustment for the presence of anxiety or depression according to the EuroQoL (moderately or extremely anxious/depressed vs not anxious/depressed); associations were similar after adjustment for this (data not shown).

\section{Discussion}

We have found a high prevalence of social isolation in our population of older community-dwelling older adults, in line with previous estimates for social isolation among older adults ranging between 15 and 40\% [49, 50], and virtually 
Table 1 Participants' characteristics

\begin{tabular}{|c|c|c|c|c|c|c|c|}
\hline & \multicolumn{3}{|l|}{ Men } & \multicolumn{3}{|l|}{ Women } & \multirow[t]{2}{*}{$p$ value } \\
\hline & $N$ & Median & IQR & $N$ & Median & IQR & \\
\hline Age (yrs) & 94 & 83.1 & $81.5-85.5$ & 82 & 83.8 & $81.5-85.9$ & 0.627 \\
\hline Height $(\mathrm{cm})$ & 94 & 171 & $168-175$ & 81 & 158 & $153-162$ & $<0.001$ \\
\hline Weight (kg) & 91 & 79.8 & $74.5-85.8$ & 82 & 66.3 & $56.8-74.8$ & $<0.001$ \\
\hline BMI $\left(\mathrm{kg} / \mathrm{m}^{2}\right)$ & 91 & 27.3 & $24.9-29.8$ & 81 & 26.2 & $23.7-29.3$ & 0.206 \\
\hline Alcohol consumption (units per week) & 94 & 2.8 & $0.2-8.6$ & 82 & 1 & $0.0-4.4$ & 0.006 \\
\hline \multirow[t]{2}{*}{ Number of NCDs } & 94 & 2 & $1-2$ & 82 & 2 & $1-3$ & 0.846 \\
\hline & Total $N$ & $N$ & $\%$ & Total $N$ & $N$ & $\%$ & $p$ value \\
\hline High blood pressure & 94 & 56 & 60 & 82 & 52 & 63 & 0.602 \\
\hline Diabetes & 94 & 18 & 19 & 82 & 18 & 22 & 0.646 \\
\hline Lung disease & 94 & 17 & 18 & 82 & 10 & 12 & 0.279 \\
\hline Rheumatoid arthritis & 94 & 2 & 2 & 82 & 4 & 5 & 0.419 \\
\hline Multiple sclerosis & 94 & 0 & 0 & 82 & 0 & 0 & - \\
\hline Cancer & 94 & 24 & 26 & 82 & 14 & 17 & 0.174 \\
\hline Vitiligo & 94 & 2 & 2 & 82 & 0 & 0 & 0.499 \\
\hline Depression & 94 & 3 & 3 & 82 & 8 & 10 & 0.073 \\
\hline Parkinson's disease & 94 & 1 & 1 & 82 & 0 & 0 & 1.000 \\
\hline Heart disease & 94 & 36 & 38 & 82 & 15 & 18 & 0.004 \\
\hline Peripheral arterial disease & 94 & 0 & 0 & 82 & 0 & 0 & - \\
\hline Osteoporosis & 94 & 8 & 9 & 82 & 22 & 27 & 0.001 \\
\hline Thyroid disease & 94 & 3 & 3 & 82 & 9 & 11 & 0.041 \\
\hline Stroke & 94 & 7 & 7 & 82 & 10 & 12 & 0.287 \\
\hline Currently married & 94 & 68 & 72 & 82 & 39 & 48 & $<0.001$ \\
\hline Social class ${ }^{\mathrm{a}}$ & 88 & & & 82 & & & 0.470 \\
\hline I-IIINM & & 37 & 42 & & 39 & 48 & \\
\hline IIIM-V & & 51 & 58 & & 43 & 52 & \\
\hline Smoker status & 94 & & & 81 & & & 0.053 \\
\hline Never & & 51 & 54 & & 57 & 70 & \\
\hline Ex & & 41 & 44 & & 22 & 27 & \\
\hline Current & & 2 & 2 & & 2 & 2 & \\
\hline Lubben Social Network Scale $<12$ & 94 & 18 & 19 & 82 & 16 & 20 & 0.951 \\
\hline Fried frailty & 84 & 11 & 13 & 78 & 14 & 18 & 0.393 \\
\hline
\end{tabular}

${ }^{\text {a}}$ Data obtained from the first pass of the HCS study (1998)

Table 2 Number of NCDs as an explanatory variable for social isolation

\begin{tabular}{|c|c|c|c|c|c|c|c|c|}
\hline & \multicolumn{4}{|c|}{ Men } & \multicolumn{4}{|c|}{ Women } \\
\hline & $N$ & Odds Ratio & $95 \% \mathrm{CI}$ & $p$ value & $N$ & Odds Ratio & $95 \% \mathrm{CI}$ & $p$ value \\
\hline Unadjusted & 94 & 0.90 & $(0.56,1.44)$ & 0.660 & 82 & 1.65 & $(1.08,2.52)$ & 0.021 \\
\hline Adjusted $^{l}$ & 84 & 0.90 & $(0.52,1.55)$ & 0.699 & 78 & 1.93 & $(1.11,3.34)$ & 0.020 \\
\hline Adjusted + frailty $^{2}$ & 76 & 1.01 & $(0.56,1.81)$ & 0.986 & 74 & 1.85 & $(1.06,3.22)$ & 0.031 \\
\hline
\end{tabular}

${ }^{1}$ Adjusted for age, BMI, social class, marital status, smoker status and alcohol consumption

${ }^{2}$ Adjusted for age, BMI, social class, marital status, smoker status, alcohol consumption and Fried frailty identical to the $19 \%$ prevalence of social isolation reported in ELSA participants with a mean (SD) age of 70.3 (16.8) years [51]. These data were collected just prior to the start of the COVID-19 pandemic; the prevalence of social isolation is now likely to be even higher. We also found that a greater number of NCDs in women was associated with a higher odds of being isolated, and this association was not affected by the presence of frailty. In contrast, no associations were 
found between the number of NCDs and being socially isolated in men.

We were interested to consider whether any possible association between the number of NCDs and social isolation could be explained by the presence of frailty after previous work in ELSA that found that social isolation predicted higher frailty levels, and higher frailty levels predicted greater social isolation [39]. In our study, adjustment for frailty did not remove associations between social isolation and NCDs in women, possibly because there were low numbers of individuals living with frailty in our population sample. Our results hence suggest that even before the onset of frailty, having a greater number of NCDs is associated with social isolation in women-but interestingly not in men.

Despite the paucity of literature on the topic, one previous study by Kristensen et al. found that, in a population of German adults with a mean (SD) age of 63.47 (11.44) years, the onset of multimorbidity was actually associated with increased social networks [27]. This diverges from what we found in our study; such discrepancy can be ascribed to the fact that our population sample is significantly older than the one examined by Kristensen and colleagues. As these authors have highlighted, the onset of physical ill health may have caused an increased need for social contact, especially through support and help [27]. This is to some extent corroborated by another study, conducted in New Zealand with participants aged between 35 and 86 years, which reported that patients with multimorbidity tend to describe social networks mainly consisting of family, support groups, and health care professionals [52]. Being considerably older, our participants are very likely to be much beyond the onset of NCDs and may have already lived with two or more conditions for a long time, by which time their social networks may have decreased in size. It must be noted that Kristensen et al. did not examine possible sex differences [27, 33]. Lastly, Tisminetzky et al. reported that, among American participants with an average age of 61 years, individuals with 4 or more comorbidities were more likely to have a limited social network compared to those with one or less conditions [53]. However, the participants in this study were not only notably younger than ours but also hospitalised individuals rather than community-dwelling adults.

The sexual dimorphism of our findings is striking. We found that the number of NCDs was associated with social isolation in women but not in men. It is possible that the number of NCDs is linked to isolation in women only as women tend to have a greater prevalence and incidence of mobility disability than men $[54,55]$ : it has been previously reported that social isolation is high among adults with disability [56] and that people with disability have fewer friends, less social support, and are more socially isolated than the general population [56-60]. Women reporting NCDs may be affected by different medical conditions to men, specifically those affecting physical performance to a greater extent $[56,57]$; for example, arthritis is more common in women, although we could find no statistically significant difference in prevalence of rheumatoid arthritis between the sexes in our sample, possibly due to the low proportion of men and women with this condition. It is also possible that co-existing depression/anxiety may mediate relationships between $\mathrm{NCD}$ and social isolation-again we found no evidence of this in our sample.

In our study, we used a simple count of NCDs rather than a complex measure such as the Charlson grading index of comorbidity [61]. A systematic review of measures of multimorbidity found that simple counts of diseases perform almost as well as complex measures in predicting outcomes such as mortality and health care utilisation [62]. In addition, the mechanisms leading from disease to social isolation can vary substantially, as there can be not only physical but also psychological reasons for social isolation. For instance, vitiligo, a skin disease characterised by a total or partial loss of melanocytes, does not cause decreased mobility (as it can instead be the case for stroke and heart disease which may thus account for social isolation); however, vitiligo, as other chronic skin conditions, is often associated with social stigmatisation and lower social acceptance [63, 64], which can in turn lead to social isolation. Similarly, high blood pressure may not directly be associated with social isolation, but medications prescribed to treat this condition may have a number of side effects (e.g. sedation, fatigue, and insomnia) [65], which can hamper one's social life and thus induce social isolation. Further work including qualitative analysis (rather than complex measures of morbidity) may be beneficial to the investigation of the relationship between multimorbidity and social isolation in this group.

Our study has a number of limitations. Our study population may not be entirely representative of the wider UK population, since all recruited participants were born in the county of Hertfordshire, were still living in their homes, and were all Caucasian. Nevertheless, it has been previously demonstrated that the HCS is representative of the general population with regard to anthropometric body build and lifestyle factors, such as smoking and alcohol intake, which was in line with data found in the European Investigation into Cancer and Nutrition Cohort (EPIC) [66]. In addition, a 'healthy' responder bias is evident within the HCS [40]. Social class was determined at the HCS baseline from the participants' then current or most recent occupation for men and never-married women, and that of the husband for married women: this is a crude assessment which might not be reflective of participants' actual occupation and, therefore, social class. An additional limitation of this study is the cross-sectional design of most of its analysis. Lastly, NCDs were self-reported and therefore recall bias cannot be ruled out. 
However, our study has also a number of strengths. Firstly, the LNS-6 provides a reliable measurement of social isolation; Rasch analysis showed unidimensionality of the overall scale, high person and item reliability and good fit of individual items with only one exception [67]. Secondly, we assessed frailty using the accepted and objective Fried criteria [68]. We are aware that other methods have been developed in order to assess frailty, but existing literature exploring the relationships between frailty and social isolation using different screening tools is limited [69]. Lastly, the HCS is a population of community-dwelling older adults that have been extensively phenotyped and well characterised with regard to lifestyle and past medical history.

\section{Conclusions}

In a cohort of community-dwelling older adults in the UK, we found that self-reported number of NCDs was associated with social isolation in women only, and that this association was not affected by frailty assessed using Fried's criteria. Healthcare professionals looking after older adults in a community setting might take our observations into consideration when completing Comprehensive Geriatric Assessments, for individuals affected by NCDs. Future studies may benefit from investigating this association longitudinally and in larger populations, and from exploring whether the association is mediated by impaired physical function and mobility disability. Qualitative studies exploring these relationships in greater detail in women would also be extremely valuable.

Funding This work was funded by the Medical Research Council.

Availability of data and material The datasets used and/or analysed during the current study are available from the corresponding author on reasonable request.

Code availability Not applicable.

\section{Declarations}

Conflict of interest Professor Cyrus Cooper has received lecture fees and honoraria from Amgen, Danone, Eli Lilly, GSK, Kyowa Kirin, Medtronic, Merck, Nestlé, Novartis, Pfizer, Roche, Servier, Shire, Takeda and UCB outside of the submitted work. Professor Elaine Dennison has received speaker honoraria from UCB, Pfizer, Lilly and Viatris. Dr Harnish Patel has received lecture fees and honoraria Health Conferences UK, Abbott and Pfizer outside of the submitted work. Gregorio Bevilacqua, Karen A Jameson, Jean Zhang, Ilse Bloom, Nicholas R Fuggle and Kate A Ward have no relevant interests to declare.

Ethical approval Ethical approval was granted by the East of England-Cambridgeshire and Hertfordshire Research Ethics Committee, reference number 11/EE/0196.
Consent to participate All participants provided informed consent prior to participation in this study. All procedures performed in studies involving human participants were in accordance with the ethical standards of the Hertfordshire Research Ethics Committee, reference number 11/EE/0196, and with the 1964 Helsinki declaration and its later amendments or comparable ethical standards.

Consent for publication Not applicable.

Open Access This article is licensed under a Creative Commons Attribution 4.0 International License, which permits use, sharing, adaptation, distribution and reproduction in any medium or format, as long as you give appropriate credit to the original author(s) and the source, provide a link to the Creative Commons licence, and indicate if changes were made. The images or other third party material in this article are included in the article's Creative Commons licence, unless indicated otherwise in a credit line to the material. If material is not included in the article's Creative Commons licence and your intended use is not permitted by statutory regulation or exceeds the permitted use, you will need to obtain permission directly from the copyright holder. To view a copy of this licence, visit http://creativecommons.org/licenses/by/4.0/.

\section{References}

1. House JS, Landis KR, Umberson D (1988) Social relationships and health. Science 241:540-545

2. Band R, Ewings S, Cheetham-Blake T et al (2019) Study protocol for 'The Project About Loneliness and Social networks (PALS)': a pragmatic, randomised trial comparing a facilitated social network intervention (Genie) with a wait-list control for lonely and socially isolated people. BMJ Open 9:e028718

3. Schrempft S, Jackowska M, Hamer M et al (2019) Associations between social isolation, loneliness, and objective physical activity in older men and women. BMC Public Health 19:1-10

4. Gale CR, Westbury L, Cooper C (2018) Social isolation and loneliness as risk factors for the progression of frailty: the English Longitudinal Study of Ageing. Age Ageing 47:392-397

5. Beridze G, Ayala A, Ribeiro O et al (2020) Are loneliness and social isolation associated with quality of life in older adults? Insights from Northern and Southern Europe. Int J Environ Res Public Health. https://doi.org/10.3390/ijerph17228637

6. de Jong-Gierveld J (1987) Developing and testing a model of loneliness. J Pers Soc Psychol 53:119-128. https://doi.org/10.1037// 0022-3514.53.1.119

7. Peplau L, Perlman D (1982) Loneliness: a sourcebook of current theory, research and therapy. John Wiley, New York

8. Courtin E, Knapp M (2017) Social isolation, loneliness and health in old age: a scoping review. Health Soc Care Commun 25:799_ 812. https://doi.org/10.1111/hsc. 12311

9. Chen YR, Schulz PJ (2016) The effect of information communication technology interventions on reducing social isolation in the elderly: a systematic review. J Med Internet Res 18:e18. https:// doi.org/10.2196/jmir.4596

10. Bevilacqua G, Jameson KA, Zhang J et al (2021) The association between social isolation and musculoskeletal health in older community-dwelling adults: findings from the Hertfordshire Cohort Study. Qual Life Res. https://doi.org/10.1007/ s11136-021-02784-7

11. Holt-Lunstad J, Smith TB, Baker M et al (2015) Loneliness and social isolation as risk factors for mortality: a meta-analytic review. Perspect Psychol Sci 10:227-237 
12. Boulos C, Salameh P, Barberger-Gateau P (2017) Social isolation and risk for malnutrition among older people. Geriatr Gerontol Int 17:286-294

13. Elovainio M, Hakulinen C, Pulkki-Råback L et al (2017) Contribution of risk factors to excess mortality in isolated and lonely individuals: an analysis of data from the UK Biobank cohort study. Lancet Public Health 2:e260-e266

14. Hakulinen C, Pulkki-Råback L, Virtanen M et al (2018) Social isolation and loneliness as risk factors for myocardial infarction, stroke and mortality: UK Biobank cohort study of 479054 men and women. Heart 104:1536-1542

15. Heikkinen R-L, Kauppinen M (2004) Depressive symptoms in late life: a 10-year follow-up. Arch Gerontol Geriatr 38:239-250

16. Koivunen K, Sillanpää E, von Bonsdorff M et al (2020) Living alone vs. living with someone as a predictor of mortality after a bone fracture in older age. Aging Clin Exp Res 32:1697-1705. https://doi.org/10.1007/s40520-020-01511-5

17. de Boissieu P, Guerin S, Suissa V et al (2021) Being useful among persons aged over 65: social representations from a cross-sectional European study. Aging Clin Exp Res 33:2565-2572. https://doi. org/10.1007/s40520-020-01767-x

18. Sebastião E, Mirda D (2021) Group-based physical activity as a means to reduce social isolation and loneliness among older adults. Aging Clin Exp Res 33:2003-2006. https://doi.org/10. 1007/s40520-020-01722-w

19. Prince MJ, Wu F, Guo Y et al (2015) The burden of disease in older people and implications for health policy and practice. The Lancet 385:549-562

20. van den Akker M, Buntinx F, Knottnerus JA (1996) Comorbidity or multimorbidity: what's in a name? A review of literature. Eur J Gen Pract 2:65-70

21. Willadsen TG, Bebe A, Køster-Rasmussen R et al (2016) The role of diseases, risk factors and symptoms in the definition of multimorbidity: a systematic review. Scand J Prim Health Care 34:112-121. https://doi.org/10.3109/02813432.2016.1153242

22. Parreira PC, Maher CG, Ferreira ML et al (2017) A longitudinal study of the influence of comorbidities and lifestyle factors on low back pain in older men. Pain 158:1571-1576

23. Bayliss EA, Ellis JL, Steiner JF (2007) Barriers to self-management and quality-of-life outcomes in seniors with multimorbidities. Ann Fam Med 5:395-402. https://doi.org/10.1370/afm.722

24. Fortin M, Bravo G, Hudon C et al (2005) Prevalence of multimorbidity among adults seen in family practice. Ann Fam Med 3:223-228

25. Vancampfort D, Koyanagi A, Ward PB et al (2017) Chronic physical conditions, multimorbidity and physical activity across 46 lowand middle-income countries. Int J Behav Nutr Phys Act 14:6. https://doi.org/10.1186/s12966-017-0463-5

26. Kingston A, Robinson L, Booth $\mathrm{H}$ et al (2018) Projections of multi-morbidity in the older population in England to 2035: estimates from the Population Ageing and Care Simulation (PACSim) model. Age Ageing 47:374-380. https://doi.org/10.1093/ageing/ afx201

27. Kristensen K, König HH, Hajek A (2019) The longitudinal association of multimorbidity on loneliness and network size: findings from a population-based study. Int J Geriatr Psychiatry 34:14901497. https://doi.org/10.1002/gps.5158

28. Renne I, Gobbens RJ (2018) Effects of frailty and chronic diseases on quality of life in Dutch community-dwelling older adults: a cross-sectional study. Clin Interv Aging 13:325

29. Jessen MAB, Pallesen AVJ, Kriegbaum M et al (2018) The association between loneliness and health-a survey-based study among middle-aged and older adults in Denmark. Aging Ment Health 22:1338-1343
30. Barlow MA, Liu SY, Wrosch C (2015) Chronic illness and loneliness in older adulthood: the role of self-protective control strategies. Health Psychol 34:870

31. Olaya B, Domènech-Abella J, Moneta MV et al (2017) All-cause mortality and multimorbidity in older adults: the role of social support and loneliness. Exp Gerontol 99:120-126

32. Wister A, Kendig H, Mitchell B et al (2016) Multimorbidity, health and aging in Canada and Australia: a tale of two countries. BMC Geriatr 16:1-13

33. Hajek A, Kretzler B, König HH (2020) Multimorbidity, loneliness, and social isolation. A systematic review. Int J Environ Res Public Health. https://doi.org/10.3390/ijerph17228688

34. Fried LP, Ferrucci L, Darer J et al (2004) Untangling the concepts of disability, frailty, and comorbidity: implications for improved targeting and care. J Gerontol A Biol Sci Med Sci 59:255-263. https://doi.org/10.1093/gerona/59.3.m255

35. Wong CH, Weiss D, Sourial $\mathrm{N}$ et al (2010) Frailty and its association with disability and comorbidity in a community-dwelling sample of seniors in Montreal: a cross-sectional study. Aging Clin Exp Res 22:54-62. https://doi.org/10.1007/bf03324816

36. Abellan van Kan G, Rolland Y, Bergman H et al (2008) The I.A.N.A Task Force on frailty assessment of older people in clinical practice. J Nutr Health Aging 12:29-37. https://doi.org/10. 1007/bf02982161

37. Bauer JM, Sieber CC (2008) Sarcopenia and frailty: a clinician's controversial point of view. Exp Gerontol 43:674-678. https://doi. org/10.1016/j.exger.2008.03.007

38. Fried LP, Tangen CM, Walston J et al (2001) Frailty in older adults: evidence for a phenotype. J Gerontol A Biol Sci Med Sci 56:M146-156. https://doi.org/10.1093/gerona/56.3.m146

39. Maltby J, Hunt SA, Ohinata A et al (2020) Frailty and social isolation: comparing the relationship between frailty and unidimensional and multifactorial models of social isolation. J Aging Health 32:1297-1308. https://doi.org/10.1177/0898264320 923245

40. Syddall H, Aihie Sayer A, Dennison E et al (2005) Cohort profile: the Hertfordshire cohort study. Int J Epidemiol 34:1234-1242. https://doi.org/10.1093/ije/dyi127

41. Syddall H, Simmonds S, Carter S et al (2019) The Hertfordshire Cohort Study: an overview [version 1; peer review: 3 approved]. F1000Research. https://doi.org/10.12688/f1000research.17457.1

42. Roberts HC, Denison HJ, Martin HJ et al (2011) A review of the measurement of grip strength in clinical and epidemiological studies: towards a standardised approach. Age Ageing 40:423-429

43. Treacy D, Hassett L (2018) The short physical performance battery. J Physiother 64:61. https://doi.org/10.1016/j.jphys.2017.04. 002

44. Lubben J, Blozik E, Gillmann G et al (2006) Performance of an abbreviated version of the Lubben Social Network Scale among three European community-dwelling older adult populations. Gerontologist 46:503-513. https://doi.org/10.1093/geront/46.4.503

45. Chang Q, Sha F, Chan CH et al (2018) Validation of an abbreviated version of the Lubben Social Network Scale ("LSNS-6") and its associations with suicidality among older adults in China. PLoS ONE 13:e0201612. https://doi.org/10.1371/journal.pone. 0201612

46. Myagmarjav S, Burnette D, Goeddeke F Jr (2019) Comparison of the 18-item and 6-item Lubben Social Network Scales with community-dwelling older adults in Mongolia. PLoS ONE 14:e0215523. https://doi.org/10.1371/journal.pone.0215523

47. Lauretani F, Russo CR, Bandinelli S et al (2003) Age-associated changes in skeletal muscles and their effect on mobility: an operational diagnosis of sarcopenia. J Appl Physiol (1985) 95:18511860. https://doi.org/10.1152/japplphysiol.00246.2003 
48. Avila-Funes JA, Helmer C, Amieva $\mathrm{H}$ et al (2008) Frailty among community-dwelling elderly people in France: the three-city study. J Gerontol A Biol Sci Med Sci 63:1089-1096. https://doi. org/10.1093/gerona/63.10.1089

49. Elder K, Retrum J (2012) Framework for isolation in adults over 50: AARP foundation isolation framework project. San Diego, CA: Research Works 16:2014

50. Taylor HO, Taylor RJ, Nguyen AW et al (2018) Social isolation, depression, and psychological distress among older adults. J Aging Health 30:229-246. https://doi.org/10.1177/0898264316 673511

51. Smith TO, Dainty JR, MacGregor A (2018) Trajectory of social isolation following hip fracture: an analysis of the English Longitudinal Study of Ageing (ELSA) cohort. Age Ageing 47:107-112. https://doi.org/10.1093/ageing/afx129

52. McKinlay E, McDonald J, Darlow B et al (2017) Social networks of patients with multimorbidity: a qualitative study of patients' and supporters' views. J Prim Health Care 9:153-161

53. Tisminetzky M, Gurwitz J, McManus DD et al (2016) Multiple chronic conditions and psychosocial limitations in patients hospitalized with an acute coronary syndrome. Am J Med 129:608-614

54. Bannerman E, Miller MD, Daniels LA et al (2002) Anthropometric indices predict physical function and mobility in older Australians: the Australian Longitudinal Study of Ageing. Public Health Nutr 5:655-662. https://doi.org/10.1079/phn2002336

55. Kadam UT, Croft PR (2007) Clinical multimorbidity and physical function in older adults: a record and health status linkage study in general practice. Fam Pract 24:412-419. https://doi.org/10.1093/ fampra/cmm049

56. Emerson E, Fortune N, Llewellyn G et al (2021) Loneliness, social support, social isolation and wellbeing among working age adults with and without disability: cross-sectional study. Disabil Health J 14:100965. https://doi.org/10.1016/j.dhjo.2020.100965

57. Equality, Commission HR (2017) Being disabled in Britain: a journey less equal. EHRC, UK

58. Krahn GL, Walker DK, Correa-De-Araujo R (2015) Persons with disabilities as an unrecognized health disparity population. Am J Public Health 105:S198-S206

59. Mithen J, Aitken Z, Ziersch A et al (2015) Inequalities in social capital and health between people with and without disabilities. Soc Sci Med 126:26-35
60. Macdonald SJ, Deacon L, Nixon J et al (2018) 'The invisible enemy': disability, loneliness and isolation. Disabil Soc 33:1138-1159

61. Charlson ME, Pompei P, Ales KL et al (1987) A new method of classifying prognostic comorbidity in longitudinal studies: development and validation. J Chronic Dis 40:373-383. https://doi.org/ 10.1016/0021-9681(87)90171-8

62. Huntley AL, Johnson R, Purdy S et al (2012) Measures of multimorbidity and morbidity burden for use in primary care and community settings: a systematic review and guide. Ann Fam Med 10:134-141. https://doi.org/10.1370/afm.1363

63. Nguyen CM, Beroukhim K, Danesh MJ et al (2016) The psychosocial impact of acne, vitiligo, and psoriasis: a review. Clin Cosmet Investig Dermatol 9:383-392. https://doi.org/10.2147/ ccid.S76088

64. Bidaki R, Majidi N, Moghadam Ahmadi A et al (2018) Vitiligo and social acceptance. Clin Cosmet Investig Dermatol 11:383386. https://doi.org/10.2147/ccid.S151114

65. Laurent S (2017) Antihypertensive drugs. Pharmacol Res 124:116-125. https://doi.org/10.1016/j.phrs.2017.07.026

66. Dik VK, Murphy N, Siersema PD et al (2014) Prediagnostic intake of dairy products and dietary calcium and colorectal cancer survival-results from the EPIC cohort study. Cancer Epidemiol Prevent Biomark 23:1813-1823

67. Gray J, Kim J, Ciesla JR et al (2016) Rasch analysis of the Lubben social network scale-6 (LSNS-6). J Appl Gerontol 35:508-528

68. Morley JE, Haren MT, Rolland Y et al (2006) Frailty. Med Clin North Am 90:837-847. https://doi.org/10.1016/j.mcna.2006.05. 019

69. Mehrabi F, Béland F (2020) Effects of social isolation, loneliness and frailty on health outcomes and their possible mediators and moderators in community-dwelling older adults: a scoping review. Arch Gerontol Geriatr 90:104119. https://doi.org/10.1016/j.archg er.2020.104119

Publisher's Note Springer Nature remains neutral with regard to jurisdictional claims in published maps and institutional affiliations. 